\title{
Pulmonary function before and after anterior spinal surgery in adult idiopathic scoliosis
}

\author{
Conroy A Wong, Ashley A Cole, Laura Watson, John K Webb, Ian D A Johnston, \\ William J M Kinnear
}

\begin{abstract}
Background - Little is known about the long term effects of anterior spinal surgery on pulmonary function in adult patients with idiopathic scoliosis. A study was therefore undertaken of pulmonary function before and after anterior spinal surgery in this group of patients.

Methods - Fourteen patients (12 women) of mean age $26 \cdot 5$ years (range $17-50,10 \geq 20$ years) were studied. All 14 patients underwent thoracotomy and anterior arthrodesis, and five also underwent posterior arthrodesis. Scoliosis curves and lung volumes were measured preoperatively and at a mean follow up of $\mathbf{3 2}$ months (range 14-49) after surgery.

Results - At long term follow up after surgery the mean (SD) Cobb angle of the thoracic curve improved from $59^{\circ}\left(25^{\circ}\right)$ to $39^{\circ}\left(18^{\circ}\right)$, a correction of $31 \%$. Despite this there was a fall in mean forced vital capacity (FVC) of 0.21 litres (95\% confidence interval $0 \cdot 04$ to $0 \cdot 38)$. In the patients who underwent anterior surgery without posterior surgery $(n=9)$ there was a fall in mean FVC of 0.31 litres $(95 \%$ confidence interval 0.12 to 0.50 ); mean forced expiratory volume in one second and total lung capacity were also reduced and there was an increase in mean residual volume. Conclusions - Forced vital capacity is reduced at long term follow up in adult patients with idiopathic scoliosis who undergo anterior spinal surgery. The fall in FVC is small and is unlikely to be of clinical significance in patients with reasonable lung function in whom surgery is planned for prevention of curve progression or improvement of cosmetic appearance and pain. However, surgical intervention should not be undertaken in an attempt to improve pulmonary function.

(Thorax 1996;51:534-536)
\end{abstract}

Keywords: idiopathic scoliosis, anterior spinal surgery, Zielke VDS instrumentation, pulmonary function, vita capacity.

Surgery

University Hospital, Nottingham NG7 2UH, UK

Correspondence to: Dr W J M Kinnear. Received 24 April 1995 Returned to author 24 July 1995

Revised version received 21 September 1995 Accepted for publication 18 December 1995 patients with idiopathic scoliosis have been extensively studied, ${ }^{1}$ few studies have assessed the effect of anterior arthrodesis. Most patients in these studies were young adolescents in whom the effects of growth on pulmonary function make interpretation of changes difficult.
We have therefore prospectively studied pulmonary function in a group of mature patients with idiopathic scoliosis before and after anterior spinal surgery.

\section{Methods}

All patients at our institution undergoing anterior spinal surgery between January 1988 and December 1993 were identified. Women under 16 years of age and men under 18 years were excluded. These age criteria were chosen because growth is complete ${ }^{2}$ at these ages in the different sexes and because adult lung volumes have been attained. ${ }^{3}$ Seventeen patients were identified, of whom three did not have follow up lung function tests at least one year after surgery. Fourteen patients (12 women) were therefore studied and their mean age was 26.5 years (range 17-50), of whom 10 were adults ( $\geq 20$ years)

Spinal curves were measured from erect anteroposterior spinal radiographs. The lateral spinal curve angle was determined according to the method of $\mathrm{Cobb}^{4}$ and the apical vertebral rotation by the Perdriolle method. ${ }^{5}$ Forced expiratory volume in one second $\left(\mathrm{FEV}_{1}\right)$ and forced vital capacity (FVC) were measured using a wedge spirometer (Vitalograph, Buckingham, UK) in a standing position before surgical correction. Residual volume (RV), functional residual capacity (FRC), and total lung capacity (TLC) were determined in a sitting position by the helium dilution method (PK Morgan, Kent, UK). All measurements were performed under standardised conditions. ${ }^{6}$ Predicted volumes were based on normal values for persons of the same age, sex, ${ }^{3}$ and corrected height (derived from arm span). ${ }^{7}$ Pulmonary function tests and spinal radiographs were repeated at a mean follow up of 32 months (median 35; range 14-49) after surgery.

All 14 patients underwent thoracotomy and anterior arthrodesis. Of these, $12 \mathrm{had}$ an anterior arthrodesis with Zielke VDS instrumentation. Three patients undergoing Zielke operations also had a posterior arthrodesis (two Harrington-Luque instrumentation, one Cotrel-Dubousset instrumentation) as a second procedure. Two patients had an anterior release and posterior instrumentation (one Universal Spine System, one Cotrel-Dubousset).

Statistical analyses were made using the "Fastat" package (Systat Inc, Evanston, Illinois, USA). Preoperative and postoperative data 
Preoperative and postoperative lung volumes in patients with idiopathic scoliosis undergoing anterior arthrodesis

\begin{tabular}{|c|c|c|c|c|c|}
\hline \multirow[t]{2}{*}{ Lung volumes } & \multicolumn{2}{|l|}{ Preoperative } & \multicolumn{2}{|l|}{ Postoperative } & \multirow[t]{2}{*}{$p$ value } \\
\hline & Mean (SD) & $\begin{array}{l}\text { Mean } \\
\text { standardised } \\
\text { residual }\end{array}$ & Mean (SD) & $\begin{array}{l}\text { Mean } \\
\text { standardised } \\
\text { residual }\end{array}$ & \\
\hline \multicolumn{6}{|l|}{$\mathrm{FEV}_{1}(\mathrm{l})$} \\
\hline All patients* & $2 \cdot 86(0 \cdot 61)$ & -1.43 & $2.72(0.55)$ & $-1 \cdot 64$ & NS \\
\hline Anterior onlyt & $3.06(0.53)$ & -0.80 & $2.82(0.50)$ & -0.95 & $<0.05$ \\
\hline \multicolumn{6}{|l|}{ FVC (1) } \\
\hline $\begin{array}{l}\text { All patients } \\
\text { Anterior only }\end{array}$ & $3.34(0 \cdot 80)$ & $-2 \cdot 17$ & $3.13(0.68)$ & $-2 \cdot 36$ & $<0.05$ \\
\hline \multicolumn{6}{|l|}{$\mathrm{FEV}_{\mathrm{l}} / \mathrm{FVC}(\%)$} \\
\hline All patients & $86 \quad(6 \cdot 6)$ & $0 \cdot 77$ & $87 \quad(5 \cdot 6)$ & 1.09 & NS \\
\hline Anterior only & $84 \quad(6 \cdot 7)$ & $0 \cdot 60$ & $85 \quad(5 \cdot 3)$ & 0.76 & NS \\
\hline \multicolumn{6}{|l|}{$R V(1)$} \\
\hline All patients & $1 \cdot 17(0 \cdot 27)$ & -1.51 & $1.26(0.32)$ & $-1 \cdot 23$ & NS \\
\hline Anterior only & $1.27(0.23)$ & -1.46 & $1.41(0.27)$ & -0.89 & $<0.05$ \\
\hline \multicolumn{6}{|l|}{ FRC (1) } \\
\hline All patients & $2 \cdot 21(0.47)$ & $-3 \cdot 32$ & $2 \cdot 21(0.47)$ & $-3 \cdot 21$ & NS \\
\hline Anterior only & $2.39(0.38)$ & $-2 \cdot 72$ & $2 \cdot 41(0 \cdot 45)$ & $-2 \cdot 61$ & NS \\
\hline All patients & $4.52(0.95)$ & $-2 \cdot 70$ & $4.33(0.80)$ & \multicolumn{2}{|c|}{ TLC (1) } \\
\hline Anterior only & $4.91(0.69)$ & $-1 \cdot 79$ & $4.65(0.59)$ & $-2 \cdot 05$ & $<0.05$ \\
\hline
\end{tabular}

$\mathrm{FEV}_{1}=$ forced expiratory volume in one second; $\mathrm{FVC}=$ forced vital capacity; $\mathrm{RV}=$ residual volume; $\mathrm{FRC}=$ functional residual capacity; TLC $=$ total lung capacity; NS = not significant.

* All patients undergoing anterior surgery $(\mathrm{n}=14)$

+ Patients undergoing anterior surgery without posterior instrumentation $(n=9)$.

were analysed with paired Student's $t$ tests and Spearman's rank correlation coefficients.

\section{Results}

The preoperative lung function data showed a moderately severe restrictive defect (table). For all patients the FVC was significantly reduced following spinal surgery by a mean $(95 \%$ confidence interval) of 0.21 litres $(0.04$ to 0.38$)$, $\mathrm{p}<0.05$ (fig 1). No changes in the other lung volumes were found. In the patients who underwent anterior surgery without posterior instrumentation the FVC was reduced by a mean of 0.31 litres $(0.12$ to 0.50$), \mathrm{p}<0.05, \mathrm{FEV}_{1}$ was reduced by 0.23 litres $(0.09$ to 0.38$), \mathrm{p}<0.05$, TLC was reduced by 0.26 litres $(0.09$ to 0.43$)$, $\mathrm{p}<0.05$, and $\mathrm{RV}$ was increased by 0.14 litres $(0.08$ to 0.20$), \mathrm{p}<0.01$.

The apical vertebra of the thoracic curves and the uppermost vertebra in the fusion pre-

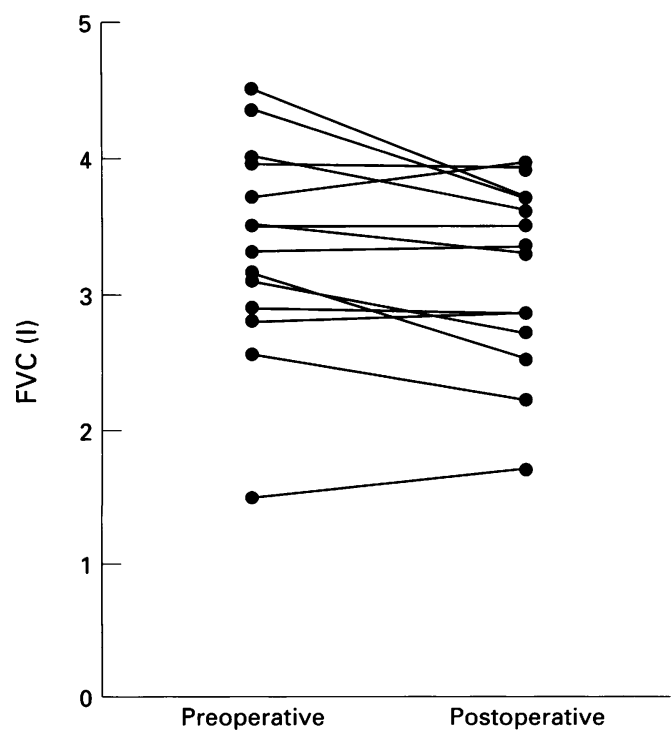

Figure 1 Preoperative and postoperative forced vital capacity (FVC) in patients with idiopathic scoliosis undergoing anterior arthrodesis.

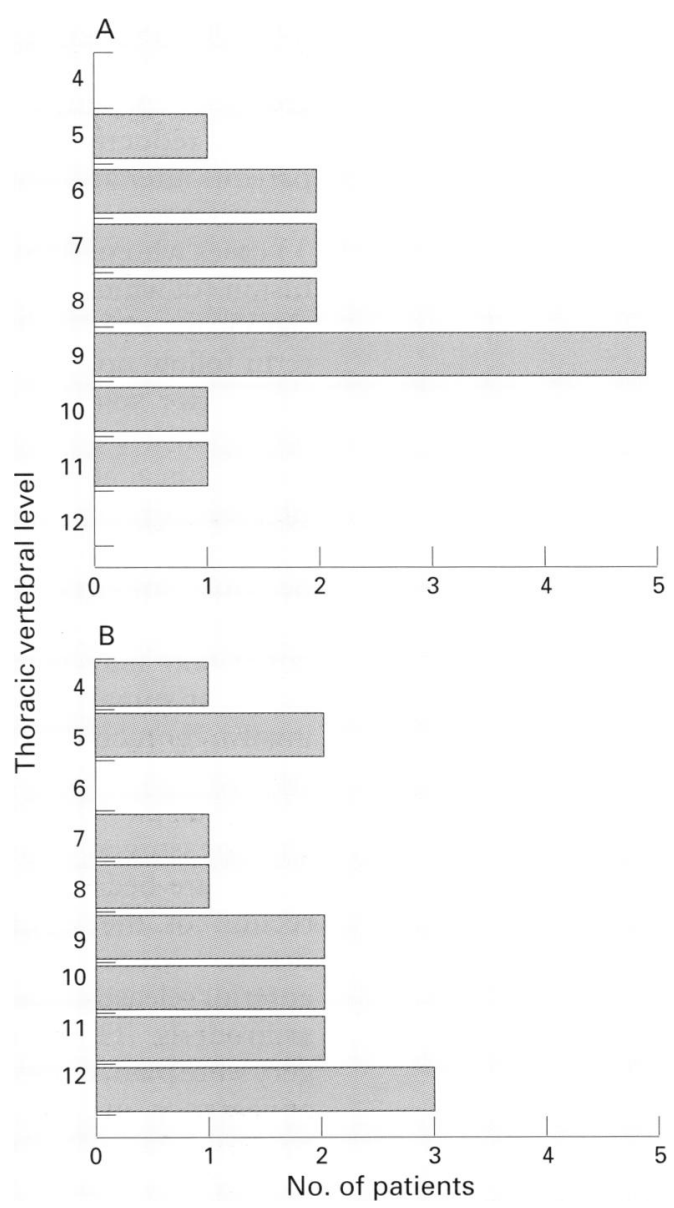

Figure 2 (A) Apical vertebra of the thoracic curves and (B) uppermost vertebra in the fusion preoperatively in patients with idiopathic scoliosis undergoing anterior arthrodesis.

operatively are shown in fig 2 . Preoperatively the mean (SD) Cobb angle was $59^{\circ}\left(24.5^{\circ}\right)$ (range $30-119^{\circ}$ ) which, on follow up after surgery, had significantly improved to $39^{\circ}\left(18^{\circ}\right)$ (range $23-88^{\circ}$ ), $p<0 \cdot 001$. The mean preoperative apical vertebral rotation was $22^{\circ}$ $\left(13.6^{\circ}\right)\left(\right.$ range $\left.0-39^{\circ}\right)$ with a non-significant reduction after surgery to $19^{\circ}\left(12^{\circ}\right)$ (range $\left.0-30^{\circ}\right)$. The mean thoracic kyphosis preoperatively was $34^{\circ}\left(15 \cdot 2^{\circ}\right.$ ) (range $6-64^{\circ}$ ), which increased non-significantly to $38^{\circ}\left(18^{\circ}\right)$ (range $2-70^{\circ}$ ) after surgery. There was a significant correlation between the preoperative Cobb angle and the preoperative FVC $\left(r_{\mathrm{s}}=\right.$ $-0.56, \mathrm{p}<0.05)$ and TLC $\left(r_{\mathrm{s}}=-0.55\right.$, $\mathrm{p}<0.05)$, but there was no significant correlation between the preoperative Cobb angle, change in Cobb angle after surgery, duration of follow up, and the change in lung volumes.

\section{Discussion}

This study has shown that FVC is reduced at long term follow up in patients with idiopathic scoliosis who undergo anterior spinal surgery despite an improvement in the thoracic spinal curve. Our study is the only series to date that specifically describes the changes in pulmonary function in adult patients with idiopathic scoliosis who undergo anterior spinal surgery (including nine of 14 patients without additional 
posterior spinal surgery). Only two other studies have assessed pulmonary function in this group of patients. Kumano and Tsuyama ${ }^{8}$ found a reduction in vital capacity in two of four patients after anterior surgery and no change in the other two. Korovessis and Zielke ${ }^{9}$ reported 33 cases who underwent anterior and posterior fusion (of which six were adults) and found no significant change in vital capacity after long term follow up.

Anterior spinal arthrodesis as in the Zielke operation is performed by a transthoracic retroperitoneal approach involving thoracotomy, rib resection, and division of the diaphragm. A deleterious effect on lung function appears to be more important in our patients than the mechanical benefit of correcting the scoliosis curve and may account for the finding that posterior spinal surgery alone (which does not involve thoracotomy) tends to have a beneficial effect on pulmonary function. ${ }^{1}$

All our patients had S-shaped curves ${ }^{10}$ and anterior surgery was chosen as the primary procedure because this results in a better correction of the spinal curves with a shorter fusion. ${ }^{11}$ More rigid spinal curves required an anterior release procedure followed by posterior arthrodesis. The primary indications for surgery were pain, curve progression, and cosmetic appearance in 10, three, and one patients, respectively. Postoperative complications included pneumonia and respiratory failure requiring tracheostomy and ventilation in one patient, pneumonia which responded promptly to antibiotics in another, and minor wound infections in two patients.

Although the reduction in FVC ( 0.21 litres) is small, there was a more marked fall in FVC $(0.31$ litres $)$ in the patients who underwent anterior surgery without posterior surgery. In patients with rapidly deteriorating pulmonary function we cannot exclude the possibility that the small fall in FVC indicates a beneficial effect of surgery in stabilising pulmonary function. However, rapidly deteriorating pulmonary function is rare in adults with idiopathic scoliosis ${ }^{12}$ and did not occur in our series.

The small reduction in FVC is unlikely to be of clinical significance in patients with reasonable lung function. However, a fall in FVC may be important in patients with poor lung function. Furthermore, surgery in adult patients with idiopathic scoliosis is associated with more frequent and serious complications. ${ }^{13}$ Our long term findings in adult patients undergoing anterior spinal surgery suggest that surgical intervention should not be undertaken to improve pulmonary function.

1 Kinnear WJM, Johnston IDA. Does Harrington instrumentaton improve pulmonary function in adolescents with idiopathic scoliosis? A meta-analysis. Spine 1993;8 1556-9.

Forfar JO, Arneil GC, eds. Textbook of pediatric medicine 2nd edn. Edinburgh:Churchill Livingstone, 1978.

3 Cotes JE. Lung function: assessment and application in medicine. 5th edn. Oxford:Blackwell Scientific Publications, 1993.

Cobb JR. Outline for the study of scoliosis. Am Acad Orthop Surg Lect 1948;5:261-75.

5 Perdriolle R. La scoliose: son etude tridimensionelle. Paris: Maloine SA, 1979

6 Quanjer PhH, Tammeling GJ, Cotes JE, Pedersen OF, Peslin R, Yernault J-C. Lung volumes and forced ventilatory flows: official statement of the European Respiratory atory flows: official statement of the European

7 Hepper NGG, Black LF, Fowler WS. Relationships of lung volume to height and arm span in normal subjects and in patients with spinal deformity. Am Rev Respir Dis 1965 patients with

8 Kumano K, Tsuyama N. Pulmonary function before and after surgical correction of scoliosis. F Bone foint Surg 1982;64A:242-8.

9 Korovessis PG, Zielke K. Does the combined ventral derotation system (VDS) followed by Harrington instrumentation improve the vital capacity in patients with idiopathic double major curve pattern scoliosis? Clin Orthop Rel Res 1992;283:130-8.

10 Wojcik AS, Webb JK, Burwell RG. An analysis of the effect of the Zielke operation on S-shaped curves in idiopathic scoliosis. The use of EVAs showing that correction of the scoliosis. The use of EVAs showing that correction of the thoracic curve occurs in its lower part: significance of the

11 Luk KDK, Leong JCY, Reyes L, Hsu LCS. The comparative results of treatment in idiopathic thoracolumbar and lumbar scoliosis using the Harrington, Dwyer, and Zielke instrumentations. Spine 1989;14:275-80.

12 Pehrsson K, Bake B, Larsson S, Nachemson A. Lung function in adult idiopathic scoliosis: a 20 year follow up. Thorax 1991;46:474-8.

13 Opitz G, Zielke K. 10-Jahresresultate bei nach Harrington operierten idiopathischen Skoliosen. Z Orthop 1990;128: 